\title{
MODIS snow cover mapping accuracy in a small mountain catchment - comparison between open and forest sites
}

\author{
J. Parajka ${ }^{1}$, L. Holko ${ }^{2}$, Z. Kostka ${ }^{2}$, and G. Blöschl ${ }^{1}$ \\ ${ }^{1}$ Institute of Hydraulic Engineering and Water Resources Management, Vienna University of Technology, Vienna, Austria \\ ${ }^{2}$ Institute of Hydrology, Slovak Academy of Sciences, Liptovský Mikuláš, Slovakia
}

Correspondence to: J. Parajka (parajka@hydro.tuwien.ac.at)

Received: 7 March 2012 - Published in Hydrol. Earth Syst. Sci. Discuss.: 28 March 2012

Revised: 21 June 2012 - Accepted: 6 July 2012 - Published: 30 July 2012

\begin{abstract}
Numerous global and regional validation studies have examined MODIS snow mapping accuracy by using measurements at climate stations, which are mainly at open sites. MODIS accuracy in alpine and forested regions is, however, still not well understood. The main objective of this study is to evaluate MODIS (MOD10A1 and MYD10A1) snow cover products in a small experimental catchment by using extensive snow course measurements at open and forest sites. The MODIS accuracy is tested in the Jalovecky creek catchment (northern Slovakia) in the period 20002011. The results show that the combined Terra and Aqua images enable snow mapping at an overall accuracy of $91.5 \%$. The accuracies at forested, open and mixed land uses at the Červenec sites are $92.7 \%, 98.3 \%$ and $81.8 \%$, respectively. The use of a 2-day temporal filter enables a significant reduction in the number of days with cloud coverage and an increase in overall snow mapping accuracy. In total, the 2day temporal filter decreases the number of cloudy days from $61 \%$ to $26 \%$ and increases the snow mapping accuracy to $94 \%$. The results indicate three possible factors leading to misclassification of snow as land: patchy snow cover, limited MODIS geolocation accuracy and mapping algorithm errors. Out of a total of 27 misclassification cases, patchy snow cover, geolocation issues and mapping errors occur in 12,12 and 3 cases, respectively.
\end{abstract}

\section{Introduction}

Snow pack is an important storage reservoir of water in many regions of the world, especially in mountains. Monitoring of its spatial and temporal changes provides essential infor- mation for water resources management and predictions of snowmelt runoff. Numerous applications of remote sensing products in the past have demonstrated that satellite images of snow cover are an attractive alternative to ground observations (Parajka and Blöschl, 2012).

In the last decade, a range of MODIS snow cover products have been used for regional mapping of snow cover changes (e.g. Kaufmann et al., 2002; Poon and Valeo, 2006; Pu et al., 2007; Sirguey et al., 2009; Tong et al. 2009b; Wang and Xie, 2009; among others). MODIS images are particularly appealing due to their high temporal (daily) and spatial $(500 \mathrm{~m})$ resolutions. Numerous validation studies examined and confirmed their accuracy and consistency against other remote-sensing products and in situ climate station data. As summarized in Parajka and Blöschl (2012), most of the MODIS accuracy assessments reported the overall accuracy between 85 and $99 \%$ during clear sky conditions. The snow cover mapping efficiency in alpine and forested regions is, however, still not well understood. There are only a few studies which include MODIS validation in forested alpine catchments. Practically all of them are based on snow measurements taken at climate stations, which are mainly open grassy sites. These sites may not represent snow cover conditions beneath the forest canopy. Climate stations in mountain regions are also often biased to lower altitudes, as they tend to be located in valleys and easily accessible places (Parajka and Blöschl, 2006). The existing studies relate the snow mapping accuracy to the dominant land cover class in a radius of typically $1 \mathrm{~km}$ around the climate station. For example, Simic et al. (2004) used land cover satellite images at $1 \mathrm{~km}$ resolution and grouped 2000 in situ measurements in Canada into four dominant classes: evergreen forest, 
deciduous forest, herb-dominated and lichen land cover type. The lowest MODIS accuracy was found for the evergreen forest class, with a minimum of $80 \%$ accuracy in April. This is somewhat smaller than the expected global minimum accuracy of $85 \%$ reported by the MODIS documentation (MODIS, 2010). The results of Simic et al. (2004) indicated a clear tendency of MODIS to overestimate snow cover extent in the evergreen forest. Similar findings were indicated by a modeling study of Nester et al. (2012). They evaluated a snow routine of an operational flood forecasting model in the alpine part of the Danube river and reported a tendency of MODIS to map more snow than was simulated by the hydrologic model in forested areas. Parajka and Blöschl (2006) examined the MODIS accuracy at 754 climate stations in Austria and used dominant land cover information as an indicator of possible tendencies in MODIS errors. Their results indicated that the largest mapping errors occurred on pastures and shrub land. The mean misclassification error for the shrub class was around $10 \%$, for pastures and forest it was around 6\%. Recently, Roy et al. (2010) examined MODIS mapping accuracy as a function of tree canopy cover. The tree canopy cover was estimated by using the MODIS Vegetation Continuous Fields dataset (Hansen et al., 2003), which indicates the proportions of cover types such as woody vegetation, herbaceous vegetation and bare ground in each MODIS pixel. The results showed a general tendency of increasing mapping errors with increasing forest cover. The MODIS underestimation dominated at lower canopy cover, while the overestimation of snow cover was observed for tree canopy cover between 60 and $80 \%$.

The objective of this paper is to assess the accuracy of MODIS snow cover mapping in a mountain forested environment relative to open sites based on extensive snow course measurements. It is anticipated that a decade of snow observations in a well documented experimental catchment may give general insights into the efficiency and accuracy of the MODIS snow cover dataset in forested mountain regions.

\section{Data}

\subsection{Study area}

The MODIS accuracy is tested in Jalovecky creek catchment (Fig. 1). This catchment is an experimental catchment of the Institute of Hydrology, Slovak Academy of Sciences. It is situated in northern Slovakia, in the highest part of the Carpathian Mountains. Catchment size is $22.2 \mathrm{~km}^{2}$ and elevation ranges between 820 and $2178 \mathrm{~m}$ a.s.l. (Fig. 2). The mean catchment elevation is $1500 \mathrm{~m}$ a.s.l. Catchment mean annual precipitation is $1550 \mathrm{~mm}$, mean annual runoff is $1015 \mathrm{~mm}$ and mean annual air temperature at catchment mean elevation is $3.5^{\circ} \mathrm{C}$. The lower part of the catchment is forested. The forest line reaches approximately $1400 \mathrm{~m}$ a.s.1. The forest is dominated by spruce and dwarf pine, which
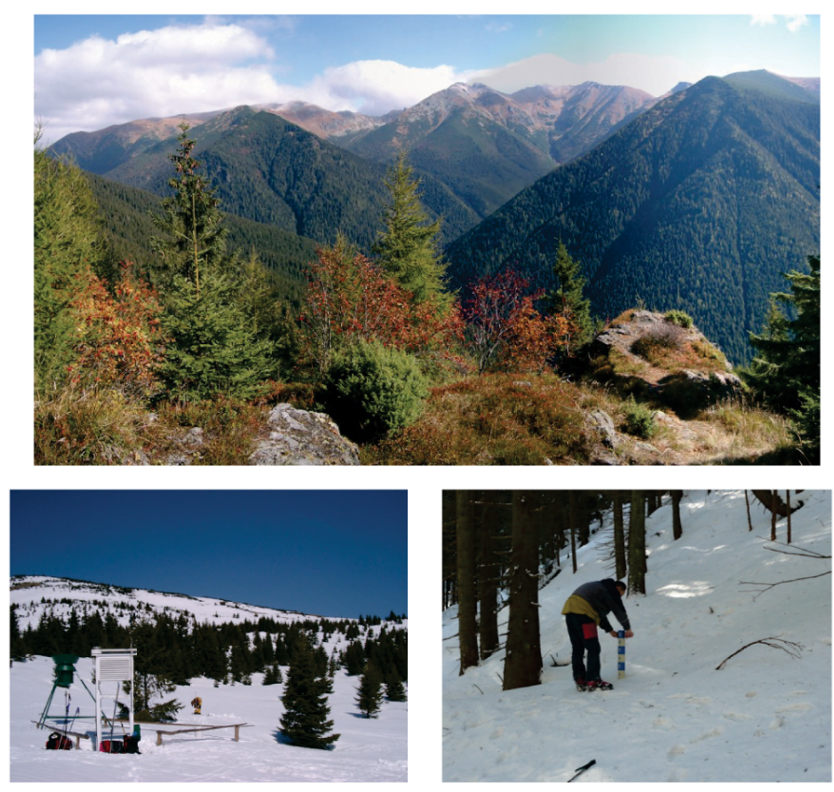

Fig. 1. View to the highest part of the Jalovecký creek catchment (upper panel), climate station and snow course locations at Červenec (bottom left panel) and snow measurement in the forest (bottom right panel).

cover 44 and $31 \%$ of the catchment, respectively (Holko and Kostka, 2010). The rest of the catchment is covered by alpine meadows and bare rocks. Since the catchment is situated in a national park, forestry activities are restricted. Most of the forest $(70 \%$ ) is older than $110 \mathrm{yr}$, and about $18 \%$ of the forest is $50-80 \mathrm{yr}$ old. The stand density (i.e. a measure of the degree of stem crowding within a stand) varies between 0.05 and 15.21 (Kostka and Holko, 1997). Most of the forest has stand density of 0.7 .

Spatial and temporal changes of the snowpack is one of the main research interests in the catchment. Snow depth and snow water equivalent (SWE) have been regularly measured along snow course profiles since 1987. Each snow profile consists of 20 snow depth measurements conducted along an approximately $25 \mathrm{~m}$ long transect and one SWE measurement conducted approximately in the middle of the transect. The measurements are performed to capture the changes in snow accumulation and melt in different altitudinal and vegetation zones. In this study, we used measurements from 16 profiles in the period 2000-2011 (Fig. 2). The number of profiles (Table 1) varies between the years, depending on the availability of personnel and weather conditions. Snow profile measurements are located both in the forest (Fig. 2, green points) and open areas (Fig. 2, yellow points) and are situated at altitudes between 750 and $1800 \mathrm{~m}$ a.s.l. (Holko and Kostka, 2008). Additionally, more detailed measurements are conducted at climate station Červenec located at the mean catchment elevation $1500 \mathrm{~m}$ a.s.l. (Figs. 1 and 2, blue point). The snow measurements at Červenec are carried 

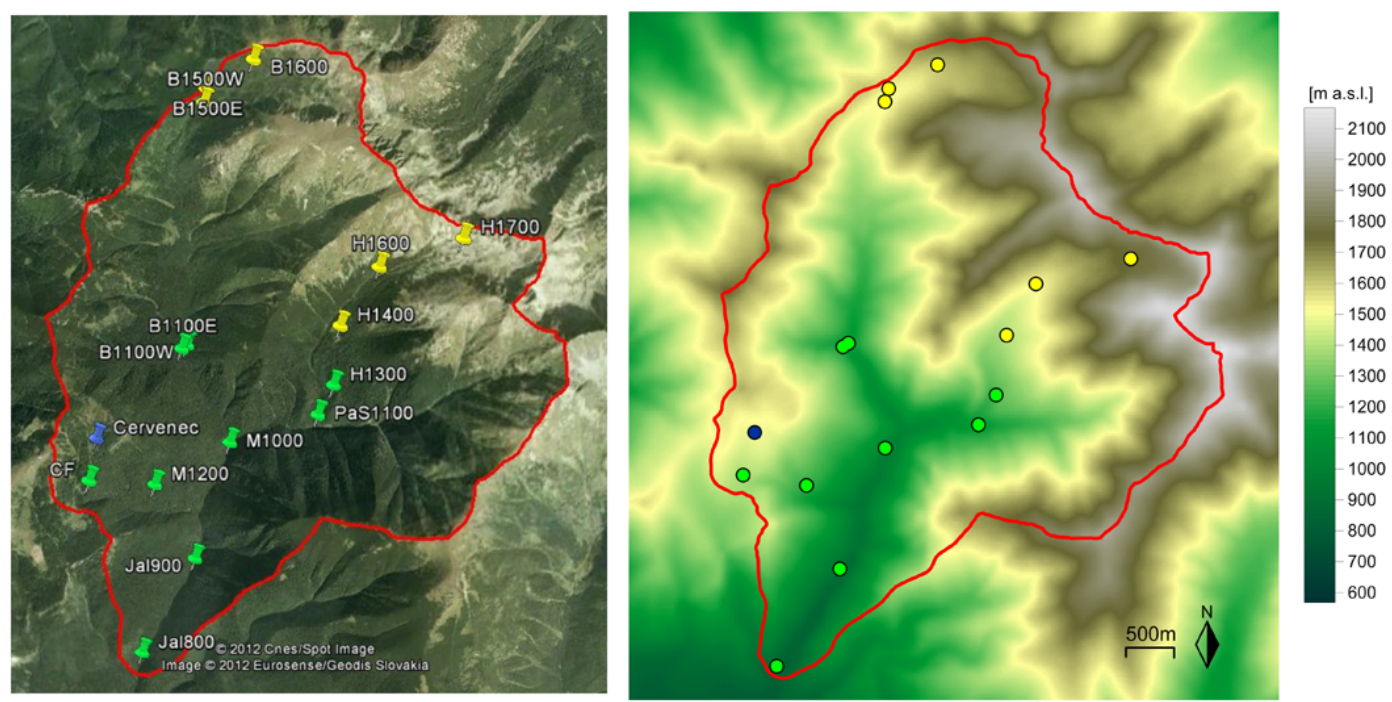

Fig. 2. Topography (screenshot from Google Earth left, digital elevation model right) and location of snow course profiles in the Jalovecky creek catchment. Measurements in the forest and open areas are indicated by green and yellow color, respectively. The blue symbol indicates the position of the reference profile at Červenec station $\left(49^{\circ} 11^{\prime} 15^{\prime \prime} \mathrm{N}, 19^{\circ} 38^{\prime} 32^{\prime \prime} \mathrm{E}\right)$.

Table 1. Number and location of snow measurements at each snow profile in the period 2000-2011.

\begin{tabular}{lrlr}
\hline Name & Elevation (m a.s.1.) & Location & $\begin{array}{r}\text { Number of snow } \\
\text { campaigns }\end{array}$ \\
\hline H1400 & 1400 & Open & 27 \\
B1500E & 1500 & Open & 24 \\
B1500W & 1500 & Open & 25 \\
H1600 & 1600 & Open & 18 \\
B1600 & 1600 & Open & 24 \\
H1700 & 1700 & Open & 29 \\
Ja1800 & 800 & Forest & 27 \\
Ja1900 & 900 & Forest & 8 \\
M1000 & 1000 & Forest & 34 \\
PaS1100 & 1100 & Forest & 25 \\
B1100E & 1100 & Forest & 27 \\
B1100W & 1100 & Forest & 24 \\
M1200 & 1200 & Forest & 17 \\
H1300 & 1300 & Forest & 29 \\
CF & 1420 & Forest & 102 \\
Cervenec & 1500 & Open/Forest & 167 \\
\hline
\end{tabular}

out every two weeks during snow accumulation and weekly or more frequently during the snowmelt period. Snow depth and SWE are measured at Červenec along 3 snow course profiles (i.e. 60 snow depth and 3 SWE measurements). The location of Červenec station is specific in that the snow profiles represent open site conditions, but in the surrounding area representing MODIS pixel size, the forest cover is approximately 40-50\% (Fig. 3).

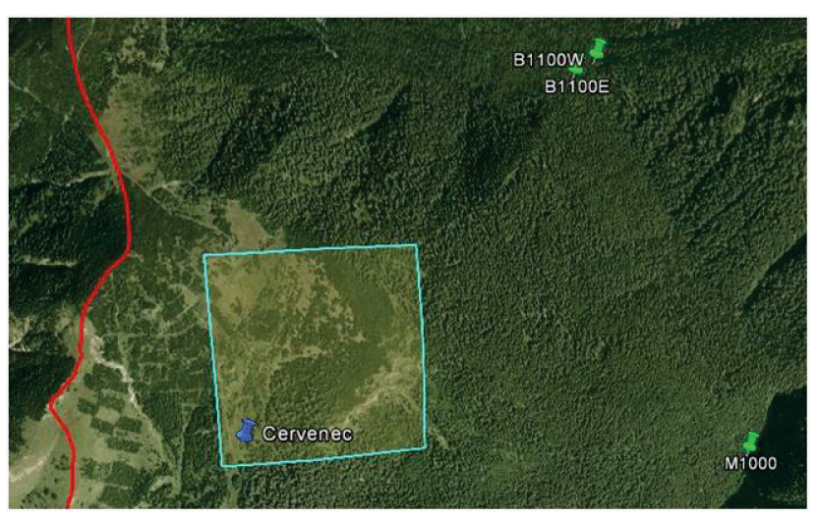

Fig. 3. Location and vegetation coverage near Červenec station (screenshot from Google Earth). The blue polygon indicates the size and position of the MODIS pixel.

\subsection{MODIS snow cover}

MODIS snow cover images are available globally at a variety of different resolutions and projections (Riggs and Hall, 2011). MODIS is an optical sensor which provides imagery of the Earth's surface and clouds in 36 discrete, narrow spectral bands from approximately 0.4 to $14.4 \mu \mathrm{m}$ (Barnes et al., 1998). The MODIS sensor is onboard two satellites, Terra and Aqua, which started observations in February 2000 and July 2002, respectively. Both satellites use the same type of MODIS instrument, but the differences in their orbits result in different viewing and cloud cover conditions. The most noticeable difference between these two satellites is the local equatorial crossing time: approximately 10:30 a.m. in a 
descending mode for the Terra and approximately 01:30 p.m. in an ascending mode for the Aqua satellite. In this study, daily datasets from Terra (MOD10A1, V005) and Aqua (MYD10A1, V005) are used. The spatial resolution of the products is $500 \mathrm{~m}$, and the geolocation accuracy is about 45-60 m (George Riggs, personal communication, also see Wolfe et al., 1998, 2002). Our study catchment is covered by the h19v04 MODIS tile. The original MODIS dataset was reprojected into conformal conic projection used in Slovakia by using MODIS Reprojection Tool (MRT, 2011).

The mapping of snow cover by using optical sensors is limited in areas where snow cover is obscured by clouds and dense forest canopies (Hall et al., 2001). In the MODIS products, a mapping of snow in forested locations is based upon a combination of vegetation and snow indices (Klein et al., 1998; Hall et al., 2001). The Normalized Difference Snow Index (NDSI) allows us to distinguish snow from many other surface features such as clouds that have high reflectance in both the visible and the short-wave infrared part of the spectrum (Hall et al., 1998). Application of the Normalized Difference Vegetation Index (NDVI) allows for the use of different NDSI thresholds for forested and non-forested pixels without compromising the algorithm performance for other land cover types. However, such a mapping approach can only be applied to the Terra data. The NDSI/NDVI test for snow in vegetated areas was disabled for Aqua imagery, because the use of band 7 resulted in too much false snow detection (Hall et al., 2006). The maximum monthly errors are expected to range from 5 percent to 9 percent for North America, and from 5 percent to 10 percent for Eurasia. The maximum aggregated Northern Hemisphere snow mapping error is estimated to be 7.5 percent. The error is highest, around 9 percent to 10 percent, when snow covers boreal forest roughly between November and April (Hall et al., 2001).

In order to reduce the effects of clouds, the methodology proposed in Parajka and Blöschl (2008) is applied in this study. It includes the combination of Terra and Aqua images and a 2-day temporal filter for snow cover mapping. The combination of Terra and Aqua merges the two MODIS snow cover products on a pixel basis. The pixels classified as clouds in the Terra images are updated by the Aqua pixel value of the same location if the Aqua pixel is snow or land. This approach combines observations on the same day, shifted by several hours. The additional 2-day temporal filter replaces cloud pixels in the combined images by the most recent preceding non-cloud observations at the same pixel within a predefined 2-day temporal window.

\section{MODIS accuracy assessment}

The accuracy of the MODIS snow cover product is quantitatively evaluated by using snow course (ground) measurements. Snow observations along the transects are considered as ground truth for the pixel that is closest to the location
Table 2. Confusion matrix defining the snow mapping accuracy (SI) by relating the ground-based snow depth observations (Ground) and the satellite snow cover from MODIS. $A$ and $B$ represent the number of cloud-free station days in a particular classification category.

\begin{tabular}{lll}
\hline Sum of station days & MODIS: SNOW & MODIS: NO-SNOW \\
\hline Ground: SNOW & $A$ & $B$ \\
Ground: NO-SNOW & - & - \\
\hline
\end{tabular}

of the snow measurements. If ground SWE measurement is larger than zero, the pixel is considered as snow covered. In the MODIS validation, only the snow cover mapping accuracy is assessed. The exact information on when snow disappeared is not available, so the snow cover mapping accuracy index (SI) relates the sum of station days with correctly mapped snow to the sum of correctly $(A)$ and falsely $(B)$ mapped snow cover by MODIS:

$\mathrm{SI}=\frac{A}{(A+B)} \cdot 100$

where $A$ and $B$ represent the number of cloud-free ground observations in a particular classification category as of Table 2 .

\section{Results}

The MODIS snow mapping accuracy (SI) at open sites is summarized in Table 3 and Fig. 4. Table 3 shows that MODIS very accurately maps snow at six open sites. With the exception of snow season 2001, the combined MODIS product perfectly matches with the ground snow observations. The overall SI accuracy of the combined product exceeds $98.3 \%$ in the period 2000-2011. The accuracy of the 2-day temporal filter of the combined Terra and Aqua product is only somewhat smaller, i.e. $97.2 \%$. The use of MODIS information from 2 preceding days results in only 2 misclassification cases (both in the snow season 2002), but significantly reduces the number of days with clouds, i.e. from $60 \%$ to less than $28 \%$ of the days with SWE observations in the period 2000-2011. The agreement between SWE observations at open sites and the MODIS snow classification is presented in detail in Fig. 4. Figure 4 shows SWE measurements at the open sites and the MODIS classification of the pixels in which the SWE was measured. In the case of cloud occurrence for days of the SWE measurements, colors represent the MODIS 2-day filter classification. Such cases are indicated by overlapping smaller (MODIS cloud) and larger (MODIS snow or land) symbols. Figure 4 shows that SWE measurements vary between 80 and $1000 \mathrm{~mm}$ in the period 2000-2011. The misclassification of snow as land by the combined MODIS images is found only for one SWE measurement $(153 \mathrm{~mm})$ in May 2001. The misclassification of the 2-day filtered MODIS is observed for two SWE 


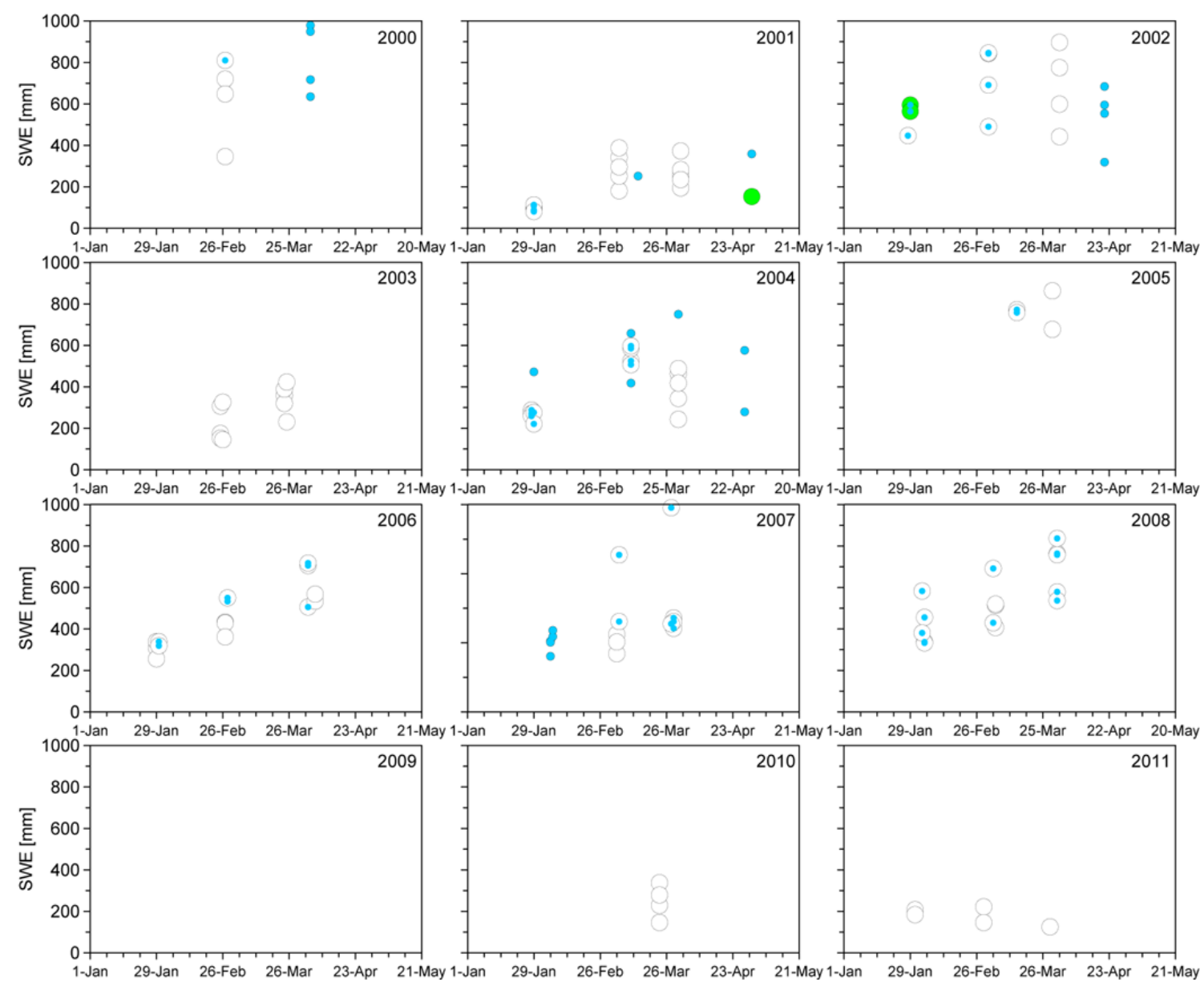

Fig. 4. Snow water equivalent (SWE) observations at open sites and MODIS classification at the respective pixels in individual snow seasons (2000-2011). Colors indicate MODIS snow (white), land (green) and cloud (blue) classifications. Overlapping of smaller (cloud) with larger (snow or land) symbols indicates the information is from the MODIS 2-day filter instead of the original cloud classification by MODIS for that day.

measurements (564 and $595 \mathrm{~mm}$ ) in January 2002. Figure 5 displays the sequence of MODIS images for both cases. The top panels (Fig. 5) present the end of the snowmelt season in May 2001. The MODIS images indicate depletion of the snow cover at open sites (i.e. elevations above $1400 \mathrm{~m}$ a.s.l.) and no snow in the lower forested part of the catchment, which is in line with ground snow observations. Although the mean snow depth at the open sites exceeded $35 \mathrm{~cm}$, a patchy snow cover is indicated by snow course measurements. The bottom panels (Fig. 5) show the cloud obstruction for the date of SWE observations and the application of the MODIS temporal filter which indicates no snow on the previous day (29 January). In this case, the open sites are situated directly at the edge of cloud coverage, which most likely indicates a false MODIS classification. This is documented by ground snow depth measurements, which exceed $120 \mathrm{~cm}$, and by continuous snow cover observed in the lower, forested part of the catchment.
The MODIS mapping accuracy at forest sites is evaluated in Table 4. From a total 293 ground snow observations (station days), the combined MODIS product correctly classifies snow at 114 profiles, misclassifies snow as land at 9 profiles, and cloud coverage obstructs snow mapping at 170 sites (58\% of the cases). The overall SI accuracy of the combined MODIS product is $92.7 \%$. Interestingly, the application of a 2-day temporal filter improves the mapping of snow at the forest sites. The temporal filter decreases the number of cloud covered sites to less than $25 \%$ ( 72 cases) and correctly classifies snow at 209 sites (station days). The misclassification of snow as land is found at 3 additional sites, which results in an overall $94.6 \%$ snow mapping accuracy. Figure 6 shows in detail the agreement between MODIS and ground SWE measurements at forest sites in the period 2000-2011. The maximum SWE measurements in individual seasons vary approximately between 100 and $600 \mathrm{~mm}$. The misclassification of snow as land is found in six snow seasons - 2003, 2004, 2005, 2007, 2008 and 2011 - and does not depend on the 
Table 3. Snow mapping accuracy (SI) at open sites. The $A, B$ and Clouds categories represent the number of station days and are defined as in Table 2.

\begin{tabular}{|c|c|c|c|c|c|c|c|c|}
\hline \multirow[b]{2}{*}{ Year } & \multicolumn{4}{|c|}{ Combined Terra+Aqua } & \multicolumn{4}{|c|}{ 2-day temporal filter of the combined images } \\
\hline & $\begin{array}{r}\text { Snow True } \\
(A)\end{array}$ & $\begin{array}{r}\text { Snow False } \\
(B)\end{array}$ & Clouds & SI $(\%)$ & $\begin{array}{r}\text { Snow True } \\
(A)\end{array}$ & $\begin{array}{r}\text { Snow False } \\
(B)\end{array}$ & Clouds & $\operatorname{SI}_{\text {FILTER }}(\%)$ \\
\hline 2000 & 3 & 0 & 13 & 100 & 4 & 0 & 12 & 100 \\
\hline 2001 & 10 & 1 & 11 & 90.9 & 14 & 1 & 7 & 93.3 \\
\hline 2002 & 4 & 0 & 15 & 100 & 9 & 2 & 8 & 81.8 \\
\hline 2003 & 10 & 0 & 2 & 100 & 10 & 0 & 2 & 100 \\
\hline 2004 & 5 & 0 & 15 & 100 & 14 & 0 & 6 & 100 \\
\hline 2005 & 2 & 0 & 2 & 100 & 4 & 0 & 0 & 100 \\
\hline 2006 & 8 & 0 & 7 & 100 & 14 & 0 & 1 & 100 \\
\hline 2007 & 3 & 0 & 12 & 100 & 10 & 0 & 5 & 100 \\
\hline 2008 & 3 & 0 & 12 & 100 & 15 & 0 & 0 & 100 \\
\hline 2009 & & & & & & & & \\
\hline 2010 & 4 & 0 & 0 & 100 & 4 & 0 & 0 & 100 \\
\hline 2011 & 5 & 0 & 0 & 100 & 5 & 0 & 0 & 100 \\
\hline Sum & 57 & 1 & 89 & 98.3 & 103 & 3 & 41 & 97.2 \\
\hline
\end{tabular}
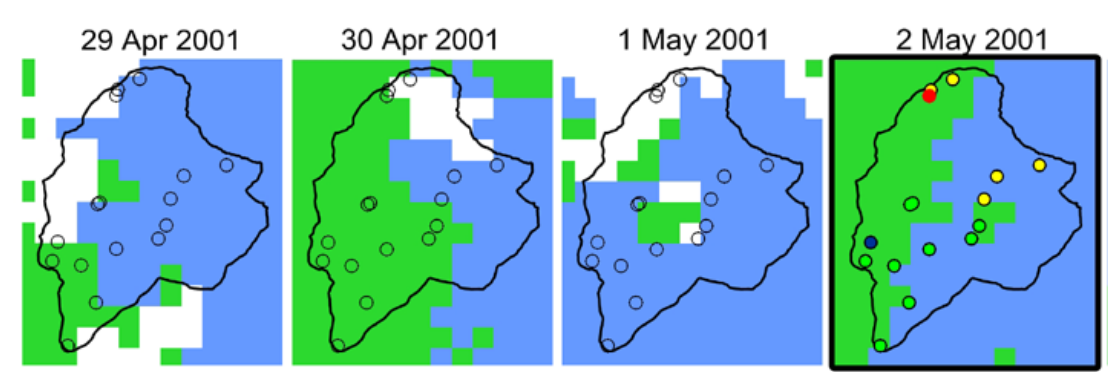

3 May 2001
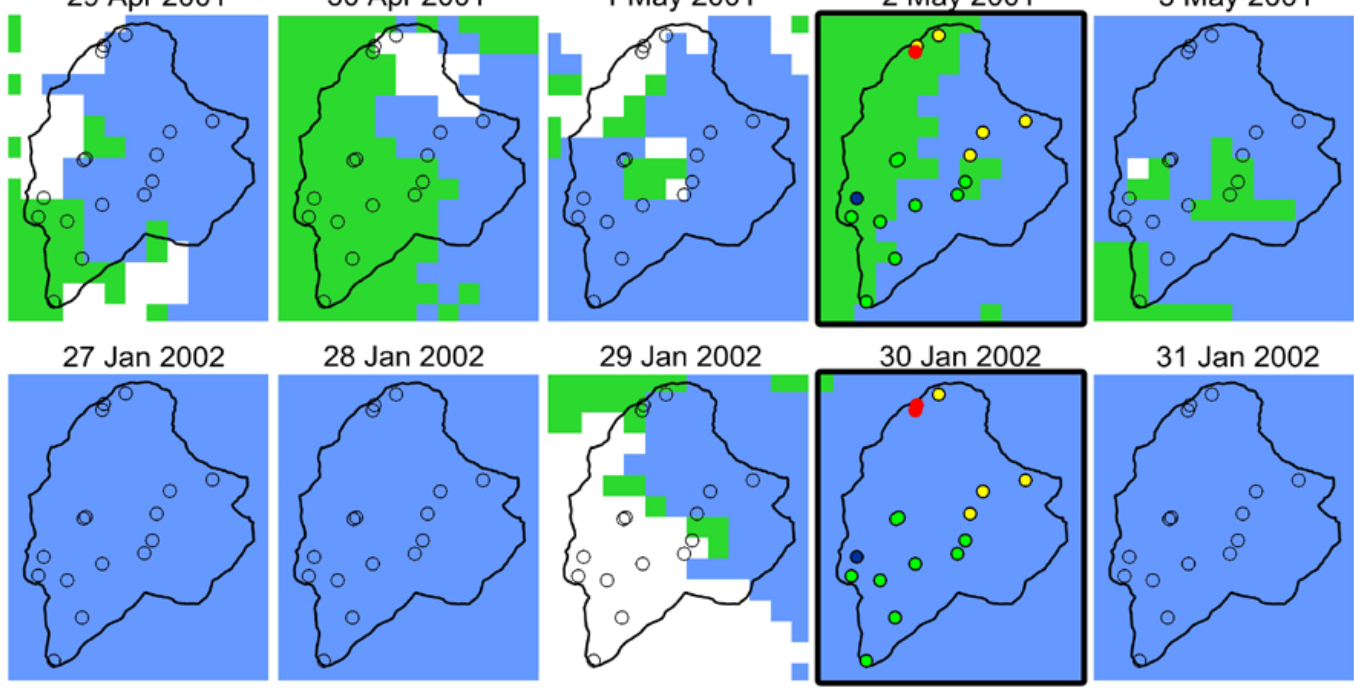

MODIS: $\square$ Land $\square$ Snow $\square$ Clouds

Site: oOpen

o Forest

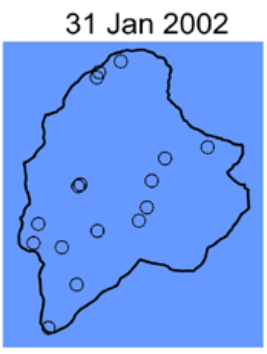

Fig. 5. Misclassification of snow as land by the combined MODIS product (top panels, May 2001) and the 2-day filter of the combined product (bottom panels, January 2002) at open sites (Fig. 4). The maps in black frames show the date of ground snow measurement; red circles indicate the sites where misclassification occurs.

maximum SWE measured in the forest. Most of the MODIS mapping errors occur at the end of the snowmelt seasons, when snow cover tends to be patchy and the mean snow depth usually does not exceed $10-15 \mathrm{~cm}$. The snow cover accuracy of the combined product decreases from perfect agreement in January and February to $84.6 \%$ in March and $90.0 \%$ in April. A similar decrease of SI to $92.0 \%$ (March) and $81.8 \%$ (April) is found for the 2-day filter. Figure 7 shows MODIS snow cover patterns for days when MODIS misclassification occurs. The mapping errors occur at 6 different snow profiles. Most of the errors are found at the forest site CF (Fig. 2) near the Červenec station and occur during patchy snow cover. Interestingly, the largest number of mapping errors occurs on 31 March 2004 (Fig. 7, second sequence of images from the top) when five sites are classified as land by MODIS. It is clear that MODIS indicates land only for a few pixels in the catchment and snow is mapped very close to each misclassified snow profile. The distance from those profiles to the nearest pixels classified as snow is between 50 and $120 \mathrm{~m}$, which is close to the limit of the MODIS geolocation 
Table 4. Snow mapping accuracy (SI) at forest sites in the period 2000-2011. The $A, B$ and Clouds categories represent the number of station days and are defined as in Table 2.

\begin{tabular}{|c|c|c|c|c|c|c|c|c|}
\hline \multirow[b]{2}{*}{ Year } & \multicolumn{4}{|c|}{ Combined Terra+Aqua } & \multicolumn{4}{|c|}{ 2-day temporal filter of the combined images } \\
\hline & $\begin{array}{r}\text { Snow True } \\
(A)\end{array}$ & $\begin{array}{r}\text { Snow False } \\
(B)\end{array}$ & Clouds & SI $(\%)$ & $\begin{array}{r}\text { Snow True } \\
(A)\end{array}$ & $\begin{array}{r}\text { Snow False } \\
(B)\end{array}$ & Clouds & SI FILTER $(\%)$ \\
\hline 2000 & 6 & 0 & 12 & 100.0 & 6 & 0 & 12 & 100.0 \\
\hline 2001 & 8 & 0 & 13 & 100.0 & 18 & 0 & 3 & 100.0 \\
\hline 2002 & 7 & 0 & 13 & 100 & 16 & 0 & 4 & 100.0 \\
\hline 2003 & 32 & 1 & 12 & 97.0 & 34 & 2 & 9 & 94.4 \\
\hline 2004 & 9 & 5 & 28 & 64.3 & 24 & 6 & 12 & 80.0 \\
\hline 2005 & 9 & 1 & 12 & 90.0 & 19 & 1 & 2 & 95.0 \\
\hline 2006 & 15 & 0 & 15 & 100.0 & 24 & 0 & 6 & 100.0 \\
\hline 2007 & 5 & 1 & 22 & 83.3 & 18 & 1 & 9 & 94.7 \\
\hline 2008 & 5 & 0 & 26 & 100.0 & 23 & 1 & 7 & 95.8 \\
\hline 2009 & 5 & 0 & 9 & 100.0 & 9 & 0 & 5 & 100.0 \\
\hline 2010 & 1 & 0 & 3 & 100.0 & 1 & 0 & 3 & 100.0 \\
\hline 2011 & 12 & 1 & 5 & 92.3 & 17 & 1 & 0 & 94.4 \\
\hline Sum & 114 & 9 & 170 & 92.7 & 209 & 12 & 72 & 94.6 \\
\hline
\end{tabular}

accuracy. Overall, from the 12 misclassification cases, 4 occur during patchy snow conditions as is indicated by profile snow depth measurements, and in 9 cases MODIS indicates snow closer than $120 \mathrm{~m}$ to the snow profile.

The MODIS snow mapping accuracy at the Červenec site is presented in Table 5 and Fig. 8. This site is specific in that the snow measurements are carried out in an open field, but from the perspective of the MODIS pixel resolution, it consists of a significant portion of forest cover. The snow mapping accuracy of combined product is only $81.8 \%$, which is significantly smaller than at the open or forest sites. This product falsely classifies snow as land on 10 days in the period 2000-2011. The application of a 2-day temporal filter increases the snow mapping accuracy to $90.1 \%$ and at the same time decreases the relative number of days with cloud coverage from $67 \%$ to less than $28 \%$. Figures 8 and 9 show that most of the mapping errors occur during the snowmelt period in April. From 12 misclassification cases of the temporal filter, 7 cases (May 2000, 2002, 2005 and April 2001, 2007 and 2010) represent patchy snow conditions, and in 4 cases there is snow mapped very close (less than $60 \mathrm{~m}$ ) to the site. If we omit days with patchy conditions from the analyses, then the snow mapping accuracy increases to $93.8 \%$ (combined MODIS) and 95.6\% (filtered MODIS). The results indicate that only in one case (20 April 2000) the misclassification error is caused by the MODIS mapping algorithm. The snow depth measurements at three snow profiles varies between 80 and $165 \mathrm{~cm}$ on this day.

\section{Discussion and conclusions}

The main objective of this study is to evaluate the MODIS snow mapping accuracy in a small mountain catchment. In comparison to existing assessments, a decade of extensive snow course measurements are used to test how accurate MODIS is at open and forest sites. A focus on a small experimental catchment has the advantage of using very detailed local knowledge and the possibility of using snow measurements carried out directly in the forest, instead of extrapolating the measurements from climate stations (grassy sites). As it is indicated by Simic et al. (2004), open site measurements may not always be representative of snow cover conditions in surrounding vegetated areas.

The accuracy assessment shows that the combination of Terra and Aqua MODIS images enables us to map snow with an overall accuracy of $91.5 \%$. The accuracies at individual sites vary between $87.5 \%$ and $100 \%$, but there is no clear dependence between mapping accuracy and topography. More clear difference is found between open and forested sites. The accuracies at sites in forest, open and mixed conditions at the Črvenec site are $92.7 \%, 98.3 \%$ and $81.8 \%$, respectively. Such accuracies correspond well with the range of accuracies presented in MODIS documentations (MODIS, 2010) and a synthesis of existing validation studies (Parajka and Blöschl, 2012). The MODIS product summary page (MODIS, 2010) states, "the maximum expected errors are 15 percent for forests, 10 percent for mixed agriculture and forest, and 5 percent for other land covers." The median of mapping accuracy of MODIS (Terra) validations in different parts of the world is about $94 \%$ (Para$\mathrm{jka}$ and Blöschl, 2012). The existing validation studies report that, despite good agreement of MODIS and available satellite and ground-based snow datasets for clear-sky conditions, clouds may severely limit the application of MODIS snow cover products. Cloud coverage depends on region and season, but, very often, it is a real problem instead of an artifact of the MODIS snow mapping algorithm. In the examined 


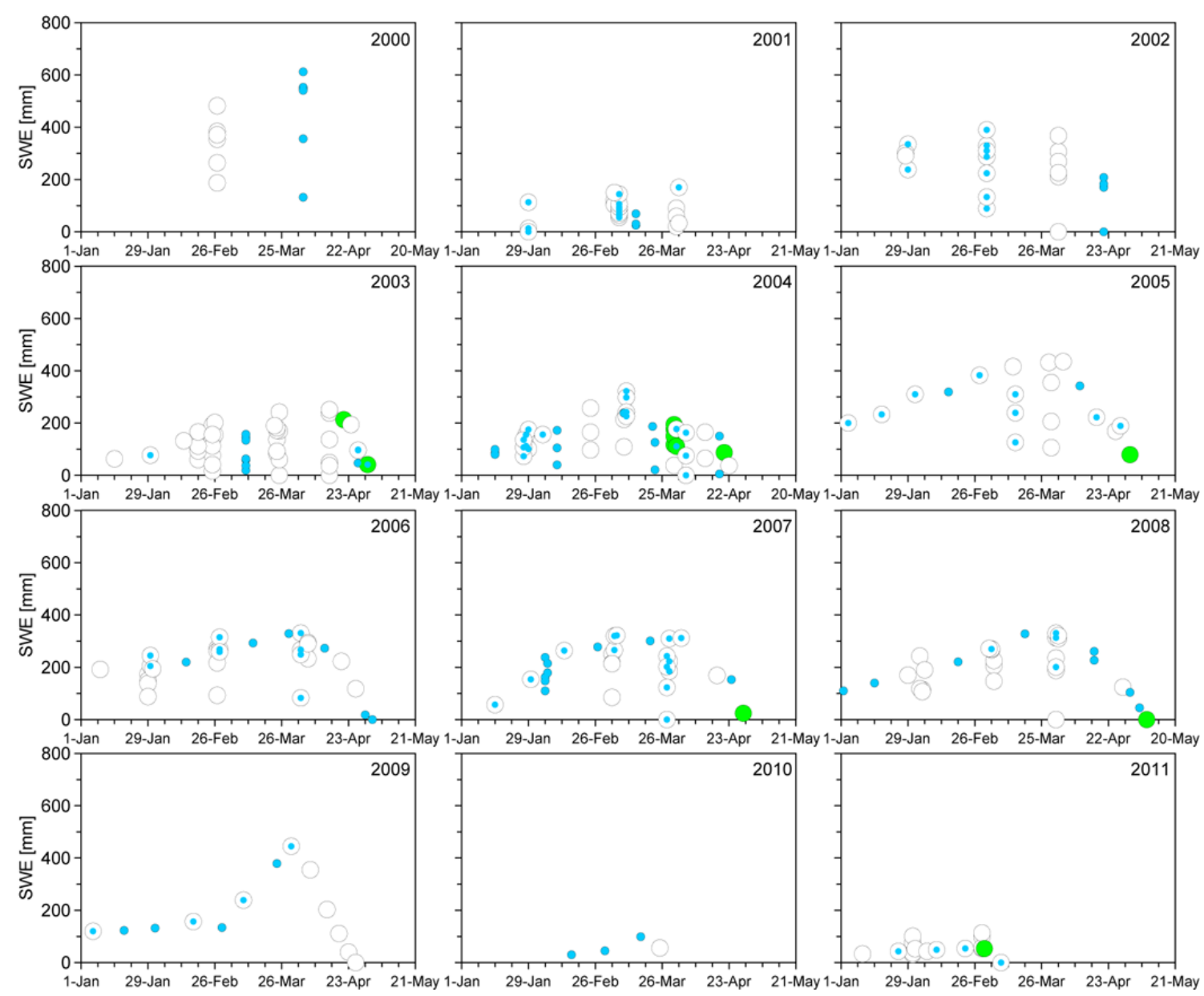

Fig. 6. Snow water equivalent (SWE) observations at forest sites and MODIS classification at the respective pixels in individual snow seasons (2000-2011). Colors indicate MODIS snow (white), land (green) and cloud (blue) classifications. Overlapping of smaller (cloud) with larger (snow or land) symbols indicates the information is from the MODIS 2-day filter instead of the original cloud classification by MODIS for that day.

experimental catchment, the relative number of days with clouds exceeds $60 \%$, which is similar to results from Austria (Parajka and Blöschl, 2006) and in Canada (Tong et al., 2009a). Interestingly, the use of the 2-day temporal filter enables a significant decrease in the number of days with cloud coverage and an increase of overall snow mapping accuracy. In total, the 2-day temporal filter decreases the number of cloudy days in the Jalovecky creek catchment to $26 \%$ and increases the snow cover mapping index to $94 \%$.

The existing studies report that the largest MODIS mapping errors occur only at a small number of sites, which are likely affected by specific local meteorological and/or physiographic conditions (e.g. low solar illumination conditions or false land/water mask along the coastline). Riggs and Hall (2011) note that "aside from potential mapping or geolocation errors, most snow detection errors are associated with non-ideal conditions for snow detection or with snow/cloud discrimination." The dataset used in this study enables a detailed assessment of the misclassification of snow as land by
MODIS. The results show that most of the mapping errors occur at the end of the snowmelt season, usually at the end of April or May. This is in line with the findings of Klein and Barnett (2003), who noted that the disagreement between in situ and remotely sensed snow observations appears to be highest in the transition zone periods at the beginning and end of the snow season. Three possible factors that lead to misclassification are found in this study. The first factor is patchy snow cover close to the ground SWE measurements. The patchy snow cover is detected by snow course measurements, where at least one of the snow depth measurements along the profile is zero. Out of a total of 27 misclassification cases, patchy snow cover occurs at 12 profiles. The second factor is the geolocation accuracy of MODIS images. The results show that in 7 cases there is snow mapped within a $60 \mathrm{~m}$ distance, and in 5 additional cases snow is indicated within less than $120 \mathrm{~m}$, which is a range indicated by Wolf et al. (2002). It is likely that some of those errors are not caused by the MODIS mapping algorithm but by the geolocation 

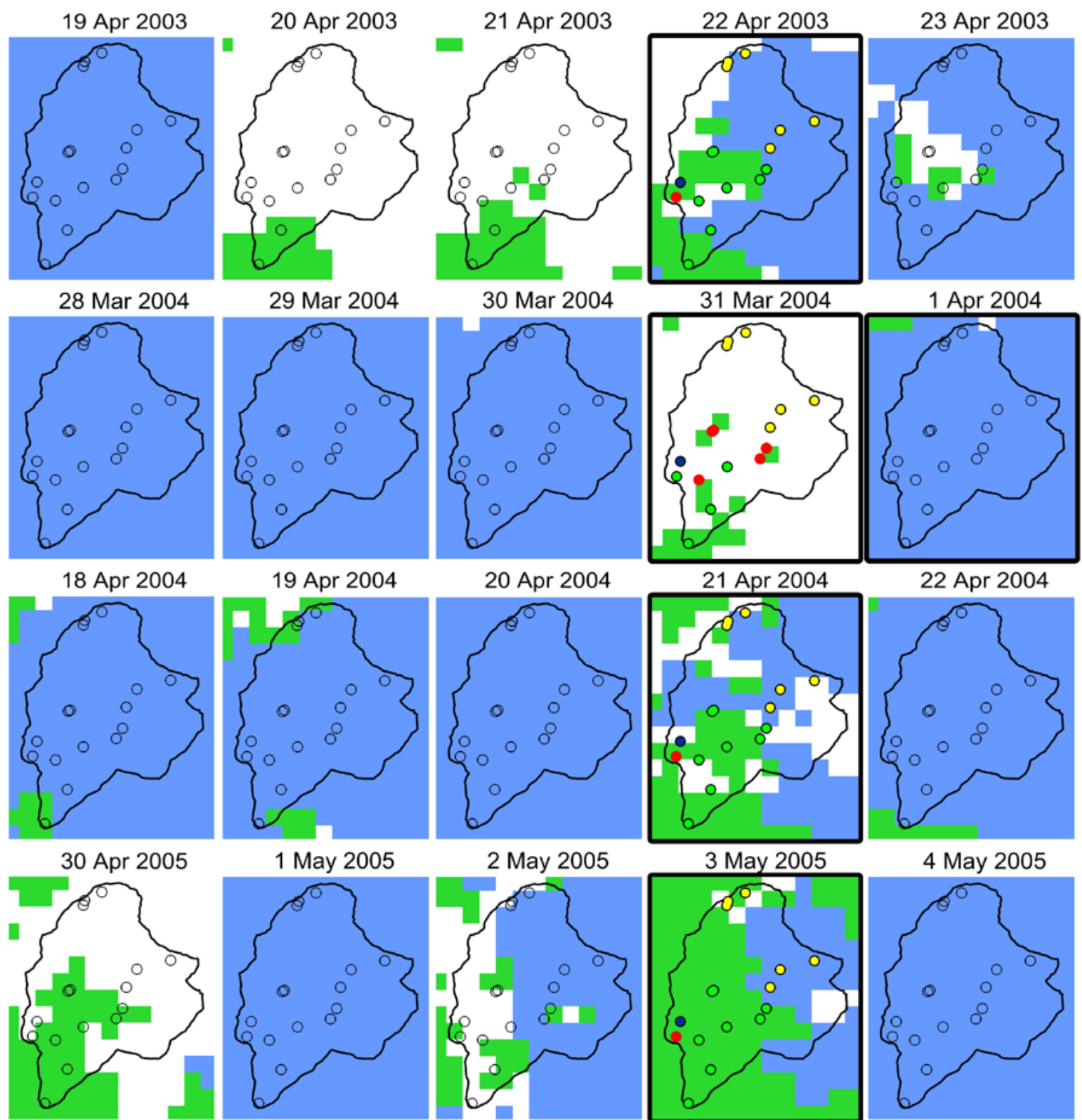

2 May 2005
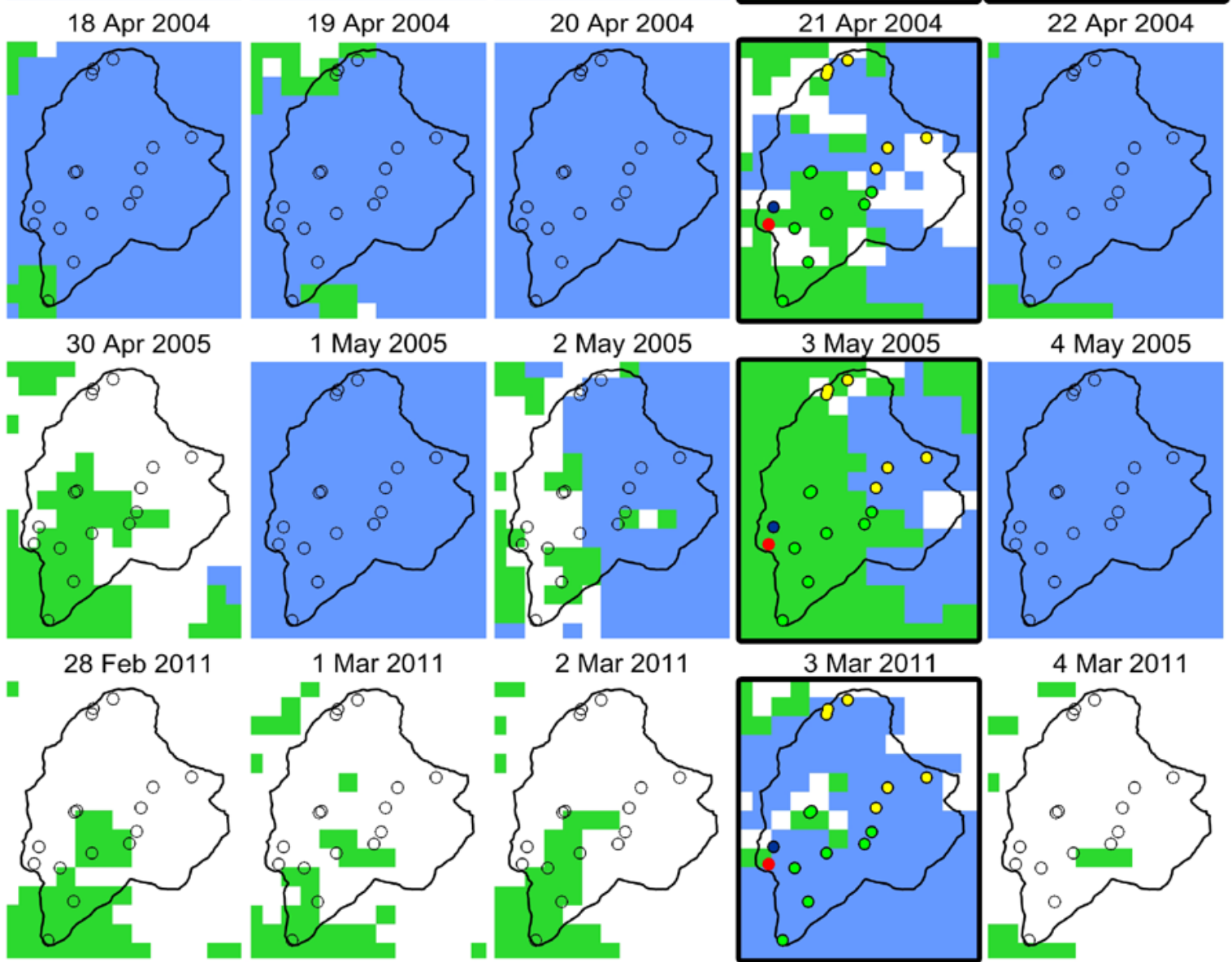

2 Mar 2011
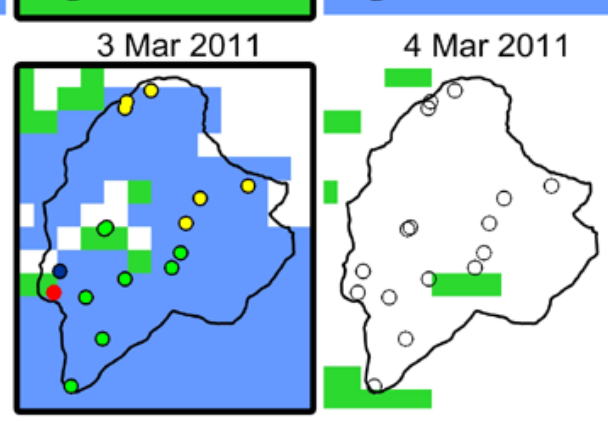

MODIS: $\square$ Land $\square$ Snow $\square$ Clouds

Site: oOpen ० Forest

- Cervenec

Fig. 7. Misclassification of snow as land by the combined MODIS product and 2-day filter of the combined product at forest sites (Fig. 6). The maps in black frames show the date of ground snow measurements; red circles indicate the sites where misclassification occurs. 


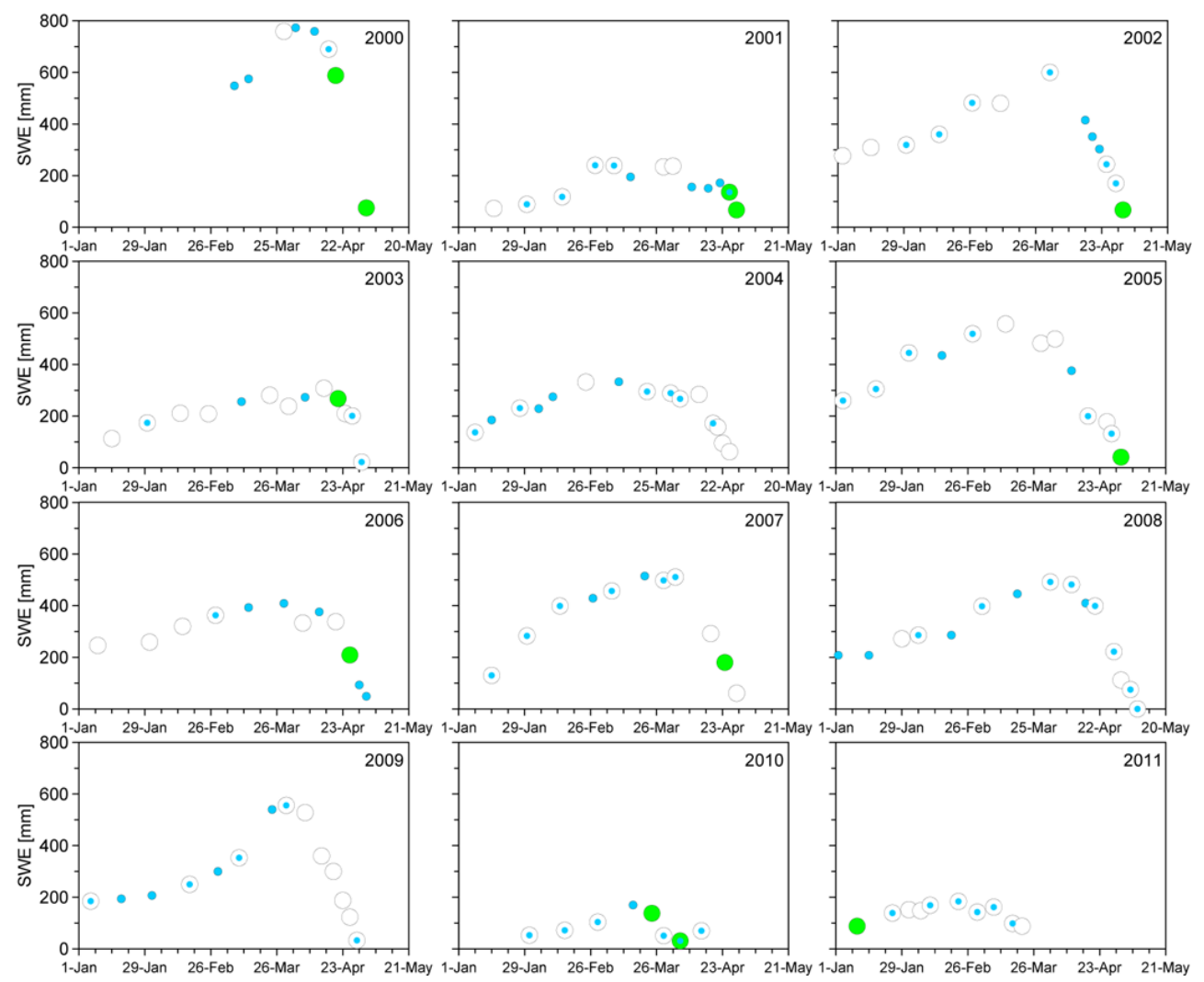

Fig. 8. Snow water equivalent (SWE) observations at Červenec station and MODIS classification at the respective pixel in individual snow seasons (2000-2011). Colors indicate MODIS snow (white), land (green) and cloud (blue) classifications. Overlapping of smaller (cloud) with larger (snow or land) symbols indicates the information is from the MODIS 2-day filter instead of the original cloud classification by MODIS for that day.

Table 5. Snow mapping accuracy (SI) at Červenec station. The $A, B$ and Clouds categories represent the number of station days and are defined as in Table 2.

\begin{tabular}{|c|c|c|c|c|c|c|c|c|}
\hline \multirow[b]{2}{*}{ Year } & \multicolumn{4}{|c|}{ Combined Terra+Aqua } & \multicolumn{4}{|c|}{ 2-day temporal filter of the combined images } \\
\hline & $\begin{array}{r}\text { Snow True } \\
(A)\end{array}$ & $\begin{array}{r}\text { Snow False } \\
(B)\end{array}$ & Clouds & SI $(\%)$ & $\begin{array}{r}\text { Snow True } \\
(A)\end{array}$ & $\begin{array}{r}\text { Snow False } \\
(B)\end{array}$ & Clouds & SI FILTER $(\%)$ \\
\hline 2000 & 1 & 2 & 13 & 33.3 & 2 & 2 & 12 & 50.0 \\
\hline 2001 & 3 & 1 & 9 & 75.0 & 7 & 2 & 4 & 77.8 \\
\hline 2002 & 3 & 1 & 12 & 75.0 & 11 & 1 & 4 & 91.7 \\
\hline 2003 & 7 & 1 & 5 & 87.5 & 10 & 1 & 2 & 90.9 \\
\hline 2004 & 5 & 0 & 12 & 100.0 & 13 & 0 & 4 & 100.0 \\
\hline 2005 & 6 & 1 & 9 & 85.7 & 13 & 1 & 2 & 92.9 \\
\hline 2006 & 5 & 1 & 7 & 83.3 & 6 & 1 & 6 & 85.7 \\
\hline 2007 & 2 & 1 & 8 & 66.7 & 8 & 1 & 2 & 88.9 \\
\hline 2008 & 3 & 0 & 13 & 100.0 & 11 & 0 & 5 & 100.0 \\
\hline 2009 & 6 & 0 & 10 & 100.0 & 12 & 0 & 4 & 100.0 \\
\hline 2010 & 0 & 1 & 7 & 0.0 & 5 & 2 & 1 & 71.4 \\
\hline 2011 & 4 & 1 & 7 & 80.0 & 11 & 1 & 0 & 91.7 \\
\hline Sum & 45 & 10 & 112 & 81.8 & 109 & 12 & 46 & 90.1 \\
\hline
\end{tabular}



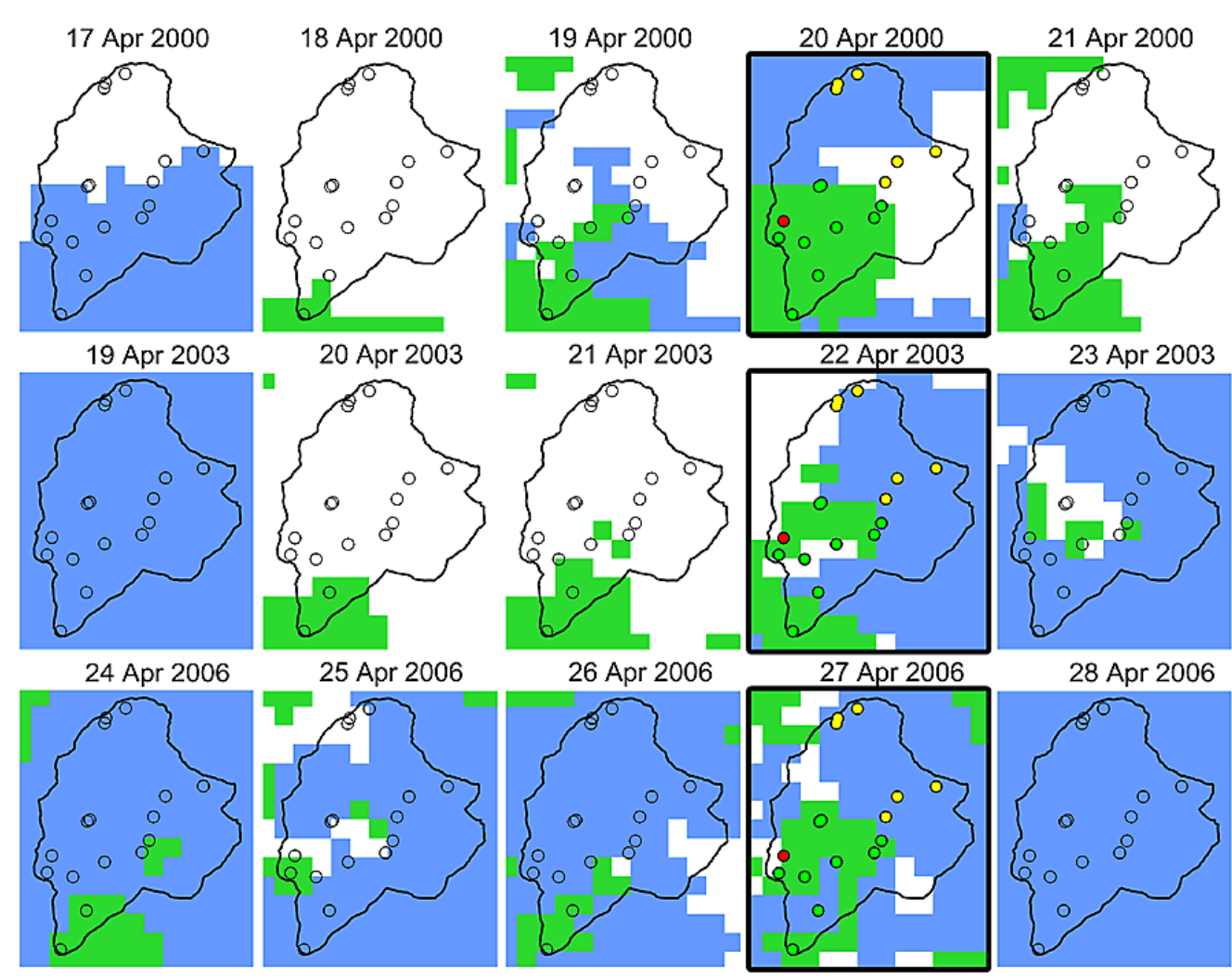

27 Apr 2006

28 Apr 2006

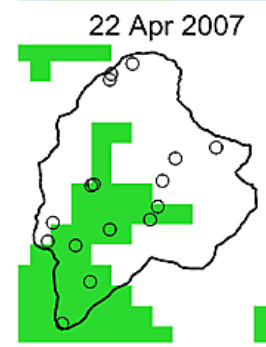

23 Apr 2007
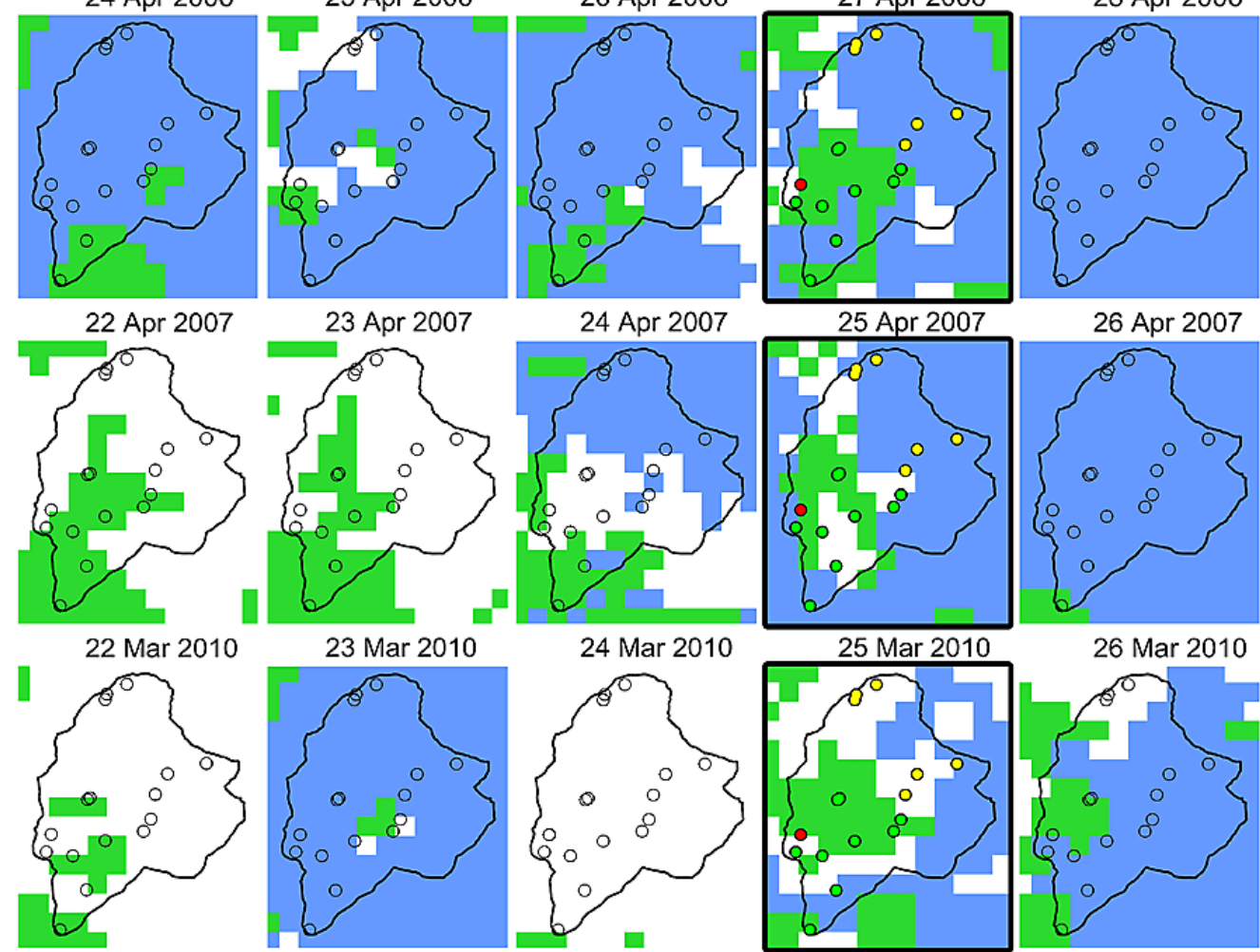

26 Apr 2007
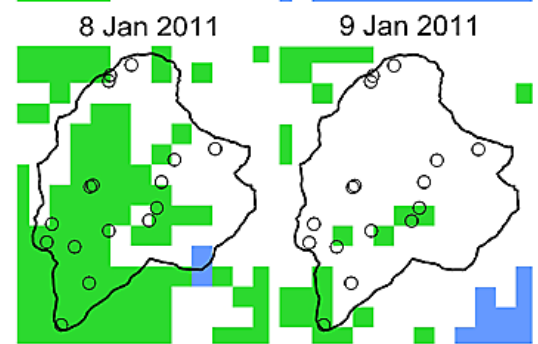

10 Jan 2011
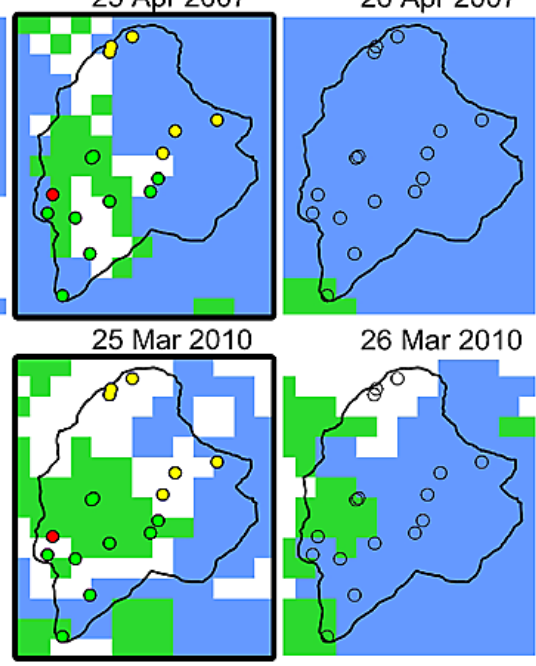

26 Mar 2010
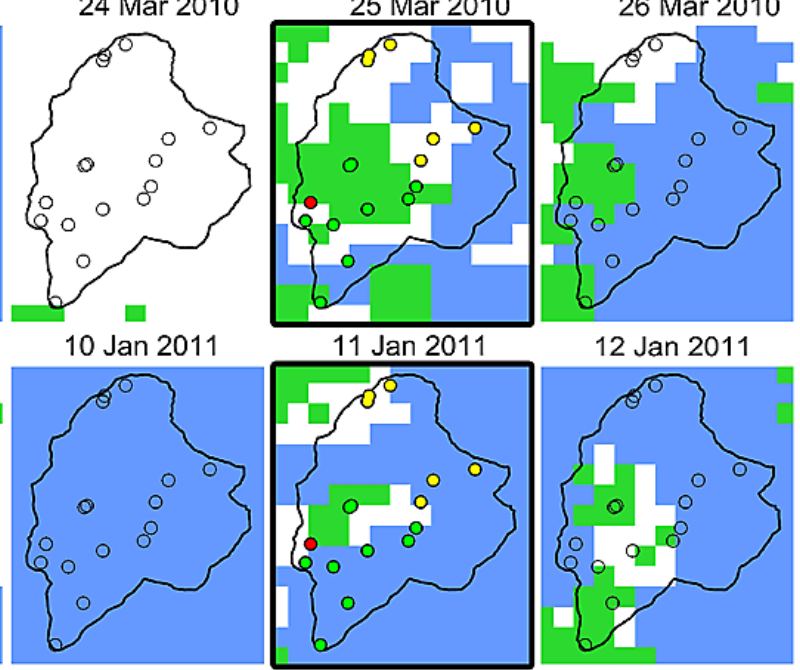

12 Jan 2011

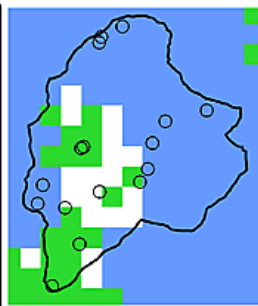

MODIS: $\square$ Land $\square$ Snow $\square$ Clouds

Site: oOpen o Forest

- Cervenec

Fig. 9. Misclassification of snow as land by the combined MODIS product and 2-day filter of the combined product at Červenec station (Fig. 8). The maps in black frames show the date of ground snow measurement; red circles indicate the site Červenec where misclassification occurs. 
itself. It would be interesting to examine some kind of spatial filter to reduce such misclassifications in the future. The third factor is the misclassification by the MODIS mapping algorithm. Three cases are identified as caused by this factor. Two of them are found at open sites and are located at the edge of cloud cover. Only one case at the Červenec station (April 2000) seems to be a distinct MODIS mapping error. However, it is beyond the scope of the study to analyze technical details of why the MODIS algorithm classifies the particular pixels as land instead of snow in those cases.

The results of this study confirm that MODIS allows accurate snow cover mapping also in forested mountain catchments. We believe that our results could be extrapolated to other regions with similar vegetation and terrain characteristics. For the future, it would be very interesting and important to observe the exact date of snow disappearance, as well as to extend such accuracy assessments to other regions, because snow in forests is an important component of the water balance in many catchments worldwide.

Acknowledgements. We would like to thank grant VEGA 2/0042/11 and the ÖAW project "Predictability of Runoff in a Changing Environment" for financial support. We greatly appreciate very constructive and helpful comments of S. Dery and an anonymous reviewer.

Edited by: M. Gooseff

\section{References}

Barnes, W. L., Pagano, T. S., and Salomonson, V. V.: Prelaunch characteristics on the moderate resolution imaging spectroradiometer (MODIS) on EOS-AM1, IEEE T. Geosci. Remote, 36, 1088-1100, 1998.

Hall, D. K., Foster, J. L., Verbyla, D. L., Klein, A. G., and Benson, C. S.: Assessment of snow-cover mapping accuracy in a variety of vegetation-cover densities in central Alaska, Remote Sens. Environ., 66, 129-137, 1998.

Hall, D. K., Riggs, G. A., and Salomonson, V. V.: Algorithm Theoretical Basis Document (ATBD) for the MODIS Snow and Sea Ice-mapping Algorithms, available at: http://modis.gsfc. nasa.gov/data/atbd/atbd_mod10.pdf, 2001.

Hall, D. K., Riggs, G. A., and Salomonson, V. V: MODIS/Terra Snow Cover Daily L3 Global $500 \mathrm{~m}$ Grid V005, Boulder, Colorado USA: National Snow and Ice Data Center, Digital media, updated daily, 2006.

Hansen, M. C., DeFries, R. S., Townshend, J. R. G., Carroll, M., Dimiceli, C., and Sohlberg, R. A.: Global percent tree cover at a spatial resolution of $500 \mathrm{~m}$ : first results of the MODIS vegetation continuous fields algorithm, Electronic media, 2003.

Holko, L. and Kostka, Z.: Hydrological characteristics of snow cover in the Western Tatra Mountains in winters 1987-2008, Folia Geographica, series Geographica-physica, ISSN 0071-6715, XXXIX, 63-77, 2008.

Holko, L. and Kostka, Z.: Hydrological processes in mountains knowledge gained in the Jalovecky Creek catchment, Slovakia.
Status and Perspectives of Hydrology in Small Basins (Proceedings of the Workshop held at Goslar-Hahnenklee, Germany, 30 March-2 April 2009), IAHS Publ. 336, Wallingford: IAHS, ISBN 978-1-907161-08-7, 84-89, 2010.

Kaufman, Y. J., Kleidman, R. G., Hall, D. K., and Martins, J. V.: Remote sensing of subpixel snow cover using 0.66 and $2.1 \mu \mathrm{m}$ channels, Geophys. Res. Lett., 29, 4 pp., 1781, doi:10.1029/2001GL013580, 2002.

Klein, A. G. and Barnett, A. C.: Validation of daily MODIS snow cover maps if the Upper Rio Grande River Basin for the 20002001 snow year, Remote Sens. Environ., 86, 162-176, 2003.

Klein, A. G., Hall, D. K., and Riggs, G. A.: Improving snow cover mapping in forests through the use of a canopy reflectance model, Hydrol. Process., 12, 1723-1744, 1998.

Kostka, Z. and Holko, L.: Soil moisture and runoff generation in a small mountain basin, Publication of the Slovak Committee for Hydrology, 2, Bratislava, ISBN 80-967808-1-6, 90 pp., 1997.

MODIS web page information at: http://nsidc.org/data/docs/daac/ modis_v5/mod10_12_modis_terra_snow_cover_5min_swath.gd. html, 2010.

MODIS Reprojection Tool (MRT): user's manual (Release 4.1), Land Processes DAAC USGS Earth Resources Observation and Science (EROS) Center, 69 pp., 2011.

Nester, T., Kirnbauer, R., Parajka, J., and Blöschl, G.: Evaluating the snow component of a flood forecasting model, Hydrol. Res., in press, 2012.

Parajka, J. and Blöschl, G.: Validation of MODIS snow cover images over Austria, Hydrol. Earth Syst. Sci., 10, 679-689, doi:10.5194/hess-10-679-2006, 2006.

Parajka, J. and Blöschl, G.: Spatio-temporal combination of MODIS images - potential for snow cover mapping, Water Resour. Res., 44, W03406, doi:10.1029/2007WR006204, 2008.

Parajka, J., and Blöschl, G.: MODIS-based Snow Cover Products, Validation, and Hydrologic Applications, in: Multiscale Hydrologic Remote Sensing Perspectives and Applications, edited by: Chang, Y. and Ni-Bin, H., CRC Press 2012, 185-212, Print ISBN 978-1-4398-7745-6, 2012.

Poon, S. K. M. and Valeo, C.: Investigation of the MODIS snow mapping algorithm during snowmelt in the northern boreal forest of Canada, Can. J. Remote Sens., 32, 254-267, 2006.

$\mathrm{Pu}, \mathrm{Z}$., Xu, L., and Salomonson, V. V.: MODIS/Terra observed seasonal variations of snow cover over the Tibetan Plateau, Geophys. Res. Lett., 34, L06706, doi:10.1029/2007GL029262, 2007.

Riggs, G. A. and Hall, D. K.: MODIS Snow and Ice Products, and Their Assessment and Applications, in: Land Remote Sensing and Global Environmental Change, edited by: Ramachandran, B., Justice, C. O., and Abrams, M. J., Springer Science+Business Media, LLC 2011, Remote Sensing and Digital Image Processing 11, Chapter 30, 681-707, doi:10.1007/978-1-4419-67497_30, 2011.

Roy, A., Royer, A., and Turcotte, R.: Improvement of springtime streamflow simulations in a boreal environment by incorporating snow-covered area derived from remote sensing data, J. Hydrol., 390, 35-44, 2010.

Simic, A., Fernandes, R., Brown, R., Romanov, P., and Park, W.: Validation of VEGETATION, MODIS, and GOES+SSM/I snow cover products over Canada based on surface snow depth observations, Hydrol. Process., 18, 1089-1104, 2004. 
Sirguey, P., Mathieu, R., and Arnaud, Y.: Subpixel monitoring of the seasonal snow cover with MODIS at $250 \mathrm{~m}$ spatial resolution in the Southern Alps of New Zealand: methodology and accuracy assessment, Remote Sens. Environ., 113, 160-181, 2009.

Tong, J., Déry, S. J., and Jackson, P. L.: Interrelationships between MODIS/Terra remotely sensed snow cover and the hydrometeorology of the Quesnel River Basin, British Columbia, Canada, Hydrol. Earth Syst. Sci., 13, 1439-1452, doi:10.5194/hess-131439-2009, 2009a.

Tong, J., Déry, S. J., and Jackson, P. L.: Topographic control of snow distribution in an alpine watershed of western Canada inferred from spatially-filtered MODIS snow products, Hydrol. Earth Syst. Sci., 13, 319-326, doi:10.5194/hess-13-319-2009, 2009 b.
Wang, X. and Xie, H.: New methods for studying the spatiotemporal variation of snow cover based on combination products of MOIDS Terra and Aqua, J. Hydrol., 371, 192-200, doi:10.1016/j.jhydrol.2009.03.028, 2009.

Wolfe, R. E., Roy, D. P., and Vermote, E.: MODIS land data storage, gridding and compositing methodology: Level 2 Grid, IEEE T. Geosci. Remote, 36, 1324-1338, 1998.

Wolfe, R. E., Nishihama, M., Fleig, A. J., Kuyper, J. R., Roy, D. P., and Storey, J. C.: Achieving sub-pixel geolocation accuracy in support of MODIS land science, Remote Sens. Environ., 83, 31-49, 2002. 